\title{
Chapter 9 \\ Biodiversity, Species Protection, and Animal Welfare Under International Law
}

\author{
Guillaume Futhazar
}

\begin{abstract}
The chapter explores the influence of the concept of animal welfare on international biodiversity law. A close examination of the recent evolution of this branch of international law shows that animal welfare has an ambivalent place in biodiversity-related agreements. Indeed, while welfare is only a faint consideration in the development of international regimes dealing with biodiversity as a whole, the concept has become an essential element for agreements dealing with the conservation of specific endangered species. Despite its role in these agreements, the place of animal welfare in international biodiversity law highlights that this corpus of rules is currently insufficient to be an effective tool for the protection of wildlife welfare. The last section of this study suggests that the adoption of international rules aiming at ensuring the protection of wild animals' welfare could serve the double purpose of strengthening the conservation purpose of biodiversity regimes while also filling the welfare gap of international biodiversity law.
\end{abstract}

\section{Introduction}

In a recent study, researchers from the Weizmann Institute of Science and the California Institute of Technology estimated that humans represent, in terms of mass, only $0.01 \%$ of all life. ${ }^{1}$ Yet, despite this low 'weight', our collective impact on the biosphere is so significant that we may very well have triggered the sixth mass extinction. ${ }^{2}$ This study adds to an already long list of demonstrations as to our impact

\footnotetext{
${ }^{1}$ Bar-On/Phillips/Milo, 'Biomass Distribution' 2018, 1-6.

${ }^{2}$ For an overview of the extent of this phenomenon, see Kolbert, Sixth Extinction 2014.

G. Futhazar $(\bowtie)$

Max Planck Institute for Comparative Public Law and International Law, Heidelberg, Germany e-mail: futhazar@mpil.de

(C) The Author(s) 2020

A. Peters (ed.), Studies in Global Animal Law, Beiträge zum ausländischen öffentlichen Recht und Völkerrecht 290, https://doi.org/10.1007/978-3-662-60756-5_9
} 
on all living things, ${ }^{3}$ and once more calls for a collective reflection on how to mitigate the inexorable human-caused erosion of the earth's biodiversity. Our influence on the environment also raises serious concerns for the living conditions of the remaining surviving life forms that are subject to considerable and sustained pressure. ${ }^{4}$ In this context, it becomes essential to examine not only what has been done to cope with this alarming erosion of life but also to deal with the toll we are inflicting on the living organisms that remain.

This chapter aims to explore the influence of the concept of animal welfare in international biodiversity law. To do so, it is necessary, as a preliminary clarification, to define these two terms and illustrate how they relate (Sect. 2). From there, this chapter will highlight the ambivalent place of animal welfare in biodiversity related regimes. Indeed, while the concept of animal welfare is practically invisible in the context of treaties dealing with biodiversity as a whole (Sect. 3), it appears that welfare is gradually becoming a sine qua non condition for conservation and sustainable use in the context of international agreements dealing with endangered species (Sect. 4). Based on this analysis, the last section will highlight the relevance of enacting specific international rules to ensure the welfare of wildlife (Sect. 5). Even though these rules might have a distinct purpose from international biodiversity law, they could nevertheless complement it in achieving conservation and sustainable development.

\section{The Scope of Animal Welfare and International Biodiversity Law: Wildlife as an Overlapping Theme}

The concept of animal welfare generally refers to the living and dying conditions of animals in the context of their different relations with humans. Animal welfare calls for the avoidance of unnecessary suffering and can consequently be understood as the condition in which an animal is free from hunger, malnutrition and thirst; free from fear and distress; free from physical and thermal discomfort; free from pain, injury and disease; and free to express normal patterns of behaviour. ${ }^{5}$ Furthermore, animal welfare is related to three overlapping dimensions: the animal's basic health and functioning; its affective state; and its natural way of living. ${ }^{6}$ Importantly, it has to be stressed that the concept of welfare makes sense only in the context of

\footnotetext{
${ }^{3}$ For instance, the Global Environmental Outlook by the United Nations Environmental Program (UNEP), or the several Global Biodiversity Outlooks produced in the context of the Convention on Biological Diversity. See Global Environmental Outlook 5 Environment for the Future We Want (Nairobi: UNEP 2012); Global Biodiversity Outlook 4 (Montréal: Secretariat of the Convention on Biological Diversity 2014).

${ }^{4}$ Ibid.

${ }^{5}$ These five 'liberties' were developed by the International Organisation for Animal Health (OIE). For an overview of the OIE's approach to animal welfare, see www.oie.int/en/animal-welfare/ animal-welfare-at-a-glance/.

${ }^{6}$ Paquet/ Darimont, 'Wildlife conservation' (2010), 179; Peters, 'Global Animal Law 2016, 11.
} 
human-animal relations. ${ }^{7}$ Indeed, an animal in its natural and undisturbed conditions may very well be subjected to events that violate its 'freedoms', such as predation or starvation. The concept of animal welfare does not suggest that such situations should be prevented but rather dictates that humans should not create conditions that negate the aforementioned freedoms. ${ }^{8}$

The influence of the idea of avoiding inflicting unnecessary suffering on animals has grown over the past decades. The increase in academic writing on the subject has been dubbed 'the animal turn' ${ }^{\prime 9}$ and has fuelled numerous public debates on the subject. ${ }^{10}$ Concurrently, states and international organisations have enacted laws and standards aimed at ensuring animal welfare in various settings (domestic animals, agriculture, and scientific experimentation...). ${ }^{11}$ Yet, most of these laws and standards concern captive animals, and the welfare of wildlife has been largely ignored. ${ }^{12}$ Considering this legal gap at the national and regional levels, the provisions regarding wildlife welfare have to be sought elsewhere and international biodiversity law seems, at first glance, to be suited for this purpose.

International biodiversity law can be understood as the corpus of international rules that aim to ensure the conservation and sustainable use of biodiversity. According to the Convention on Biological Diversity (CBD) ${ }^{13}$ biodiversity refers to:

the variability among living organisms from all sources including, inter alia, terrestrial, marine and other aquatic ecosystems and the ecological complexes of which they are part; this includes diversity within species, between species and of ecosystems. ${ }^{14}$

Biodiversity is an encompassing concept and consequently this branch of international environmental law can take many forms, from agreements dealing with biodiversity as a whole ${ }^{15}$ to treaties aiming at preserving a specific ecosystem at the

\footnotetext{
${ }^{7}$ As underlined by numerous commentators, the distinction between humans and animals is misleading since we are also, biologically speaking, animals. It would be more accurate to use the terms 'human animal' and 'non-human animal'. However, for the sake of brevity, this contribution will use the terms 'human' and 'animal', though the exact distinction should be kept in mind. ${ }^{8}$ In sum, welfare is not about eradicating suffering, which can be an integral part of the natural existence of animals. The main logic is to avoid causing additional and unnecessary suffering.

${ }^{9}$ This trend has been the subject of abundant comments. For a brief overview, see Weil, 'Report on the Animal Turn' 2010.

${ }^{10}$ For instance, by revealing footage of slaughter houses, the French association 'L-214' has generated a widely mediatised controversy. See Garric, 'L214, la méthode choc pour dénoncer les abattoirs', Le Monde (29 March 2016).

${ }^{11}$ The 'Global Animal Law' project has compiled a database of all national legislations regarding animal rights and welfare. See www.globalanimallaw.org/database/national/index.html.

${ }^{12}$ For the French legal system, see Nouët, 'L'Animal Sauvage' 2013. In her general study of animal law across countries, Sabine Brels concludes that, currently, free wild animals are the forgotten subjects of animal law. See Brels, Droit du Bien-Être Animal 2017a, 418.

${ }^{13}$ Convention on Biological Diversity (CBD), 5 June 1992, 1760 UNTS 79.

${ }^{14}$ Art. 2. Use of terms.

${ }^{15}$ Mainly the Convention on Biological Diversity (CBD), 1992 (n. 13).
} 
global or regional level ${ }^{16}$ or specialised conventions with the purpose of preserving certain endangered species. ${ }^{17}$ These latter specialised conventions-which together are sometimes referred to as 'international wildlife law, ${ }^{18}$ - stress that species are integral components of the ecosystems in which they live. Their conservation and sustainable use are therefore a prerequisite for the preservation of biodiversity as a whole. Furthermore, several studies have shown that the welfare of the individuals that make up a species is an important aspect for the conservation of the population as a whole. ${ }^{19}$ Accordingly, it is possible to infer that animal welfare is taken into account in international biodiversity law since it contributes to the health of species as a whole.

However, as the following sections will show, the place of animal welfare in international biodiversity law is ambiguous. In international agreements dealing with biodiversity in general, animal welfare appears to be a very minor consideration, while in the context of international conventions dealing specifically with the issue of endangered species, animal welfare is gradually becoming an essential element for conservation and sustainable use.

\section{Animal Welfare: An Absent Topic in General International Biodiversity Law}

The most emblematic biodiversity-related international agreement is arguably the Convention on Biological Diversity (CBD) ${ }^{20}$ Despite being weakly normative, ${ }^{21}$ this agreement has had a major impact on the general development of international biodiversity law. ${ }^{22}$ Several conservation principles that were developed within its

\footnotetext{
${ }^{16}$ For instance, on specific ecosystems, the Convention on Wetlands of International Importance especially as Waterfowl Habitat (Ramsar Convention), 2 February 1971, 996 UNTS 250. Regional instruments are numerous; for marine ecosystems, one could quote the Convention for the Protection of the Mediterranean Sea Against Pollution (Barcelona Convention), 16 February 1976, 1102 UNTS 107; for terrestrial ecosystems, see the Convention on the protection of the Alps (Alps Convention), 6 April 1993, 1917 UNTS 135.

${ }^{17}$ For instance, the Convention on the Conservation of Migratory Species of Wild Animals (CMS), 1 November 1983, 2742 UNTS 197.

${ }^{18}$ For a general overview of this field, see Bowman/Davies/Redgwell, Lyster's International Wildlife Law 2010.

${ }^{19}$ The last section of this chapter will further develop this notion.

${ }^{20}$ The CBD was one of the three multilateral agreements adopted following the Rio Summit on the environment in 1992 together with the United Nations Framework Convention on Climate Change and the United Convention to Combat Desertification.

${ }^{21}$ Most of the obligations laid down in the convention are tempered by the following provision: 'as far as possible and as appropriate'.

${ }^{22}$ For an overview, see Morgera/Razzaque (Eds.), Biodiversity and Nature Protection Law 2017. Each chapter in this book deals with a specific topic where the influence of the CBD is highlighted (island biodiversity, biosafety, access to genetic resources and so on).
} 
institutions were subsequently adopted by the members of other multilateral environmental agreements (for instance, the ecosystem approach ${ }^{23}$ or the Addis Ababa principles on sustainable use of biodiversity ${ }^{24}$ ), and its current strategic plan and 'Aichi Targets ${ }^{25}$ have become a major reference point for the implementation of the 'biodiversity cluster'. ${ }^{26}$ Still, the question of animal welfare is never once addressed in the provisions of the CBD and is, at best, an incidental concern in the corpus of decisions taken by its parties in order to support its implementation.

It can also be said that the heavily anthropocentric and holistic approach that is inherent to the CBD prevents animal welfare considerations to be included in its scope. The development of the ecosystem approach principle is particularly illustrative of this bias. ${ }^{27}$ The ecosystem approach calls for appropriate consideration of the entirety of each ecosystem (constituents and processes) in order to ensure that human society benefits from healthy ecosystems. ${ }^{28}$ Though this principle does not directly go against the concept of animal welfare, its strong emphasis on human benefits ${ }^{29}$ and its holistic approach is illustrative of the opposition that exists between environmental ethics (anthropocentric and holistic) and animal ethics (zoocentric and individualist). ${ }^{30}$

\footnotetext{
${ }^{23}$ CBD, Decision V/6 (May 2000), Ecosystem Approach. This approach had an impact on the conceptualisation of key concepts for the Ramsar Convention. On this topic, see Davison/Coates, 'Ramsar Convention' 2011, 199-205.

${ }^{24} \mathrm{CBD}$, Decision VII/12 (April 2004), Sustainable Use (art. 10). The Addis Ababa Principles comprised in this decision were subsequently adopted by the members of the CITES. CITES, Resolution Conf. 13.2, Rev. Cop.14 (2007), Sustainable use of biodiversity: Addis Ababa Principles and Guidelines.
}

${ }^{25}$ CBD, Decision X/2 (October 2010), The Strategic Plan for Biodiversity 2011-2020, including the Aichi Biodiversity Targets.

${ }^{26}$ The term 'biodiversity cluster' refers to the main multilateral environmental agreements in the field of biodiversity and ecosystems. These conventions are, in chronological order, the Convention on Wetlands of International Importance Especially as Waterfowl Habitat (Ramsar Convention), 1971 (n. 16); the Convention for the Protection of the World Cultural and Natural Heritage (World Heritage Convention), 16 November 1972, 1037 UNTS 151; Convention of International Trade in Endangered Species of Wild Fauna and Flora (CITES), 3 March 1973, 993 UNTS 243; the Convention on Migratory Species of Wild Animals (CMS), 1983 (n. 17); the Convention on Biological Diversity (CBD), 1992 (n. 13), and the International Treaty on Plant Genetic Resources for Food and Agriculture (ITPGRFA), 3 November 2001, 2400 UNTS 303. For a more detailed account of this 'cluster', see UNEP-WCMC, Promoting Synergies within the Cluster of Biodiversity-Related Multilateral Environmental Agreements (Cambridge: UNEP-WCMC 2012). On the diffusion of the Aichi Targets and their legal influence, see Futhazar, 'Diffusion' 2015.

${ }^{27}$ It should be noted that this principle exists in various forms in different international regimes. On the versatility of this notion, see De Lucia, 'Competing Narratives' 2015.

${ }^{28}$ Ibid., 'Ecosystems should be managed for their intrinsic values and for the tangible or intangible benefits for humans, in a fair and equitable way'.

${ }^{29} \mathrm{CBD}$, Decision V/6, 'Ecosystems should be managed for their intrinsic values and for the tangible or intangible benefits for humans, in a fair and equitable way' (emphasis added).

${ }^{30}$ To simplify, the main divide between environmental ethics and animal ethics is that environmental ethics consider the environment as a whole and see animals as components of species and not as individuals. On the other hand, animal ethics consider the animal in its individuality and is therefore 
Despite this overarching holistic approach to conservation, the decisions of the members of the CBD are not entirely devoid of animal welfare considerations. For instance, art. 8.h of the convention calls for the prevention of the introduction of invasive species and, in cases where this prevention fails, their control or eradication. ${ }^{31}$ To implement this article, the parties and institutions of the CBD have developed a series of guidelines that state on several occasions that the eradication of invasive species has to be done in an 'ethically acceptable' way. ${ }^{32}$ Of course this mention of ethics is vague but it does offer an entry point for considerations of animal welfare as the topic gains importance at the international level and in national contexts. $^{33}$

Interestingly, the provisions and developments of the CBB concerning the conservation of biodiversity are mirrored in other agreements, be they on specific conservation issues (for instance wetlands ${ }^{34}$ ) or on specific regions (the Mediterranean $^{35}$ or the Alps, ${ }^{36}$ for instance). Consequently, as far as agreements concerning biodiversity as a whole are concerned, it is clear that animal welfare is not the main consideration for states or institutions, who are committed instead to a holistic approach for conservation and sustainable use. ${ }^{37}$

Recent developments in other international fora tend to reinforce this assessment. For instance, resolution 72/223 of the United Nations General Assembly on Harmony with Nature clearly highlights the ecosystemic and holistic approach of the UN with regards to the environment. ${ }^{38}$ It can also be said that the recent decision of

concerned with welfare and rights. On the divide between these approaches, see Sagoff, 'Animal Liberation' 1983; Guichet, 'La question animale' 2013.

${ }^{31}$ Invasive alien species are a serious threat to environmental integrity, even more so than climate change in certain countries. See IPBES, IPBES/2/16/Add.3 (2013), Initial scoping for the thematic assessment of invasive alien species and their control, § 4.

${ }^{32}$ The guidelines can be found in CBD, Decision V/8 (May 2000), Alien species that threaten ecosystems, habitats or species.

${ }^{33}$ The same mention of ethics is also present in the Addis Ababa principles (n. 24).

${ }^{34}$ Davison/Coates, 'The Ramsar Convention' 2011.

${ }^{35}$ Barcelona Convention, Decision IG.17/6 (2008), Implementation of the ecosystem approach to the management of human activities that may affect the Mediterranean marine and coastal environment.

${ }^{36}$ The Protocol on Nature Protection and Landscape Conservation of the Alpine Convention reflects the CBD's orientations. CBD, Memorandum of Cooperation between the Convention on Biological Diversity and the Alpine Convention and the Carpathian Convention (May 2008).

${ }^{37}$ Of course, some counter examples can be mentioned, such as the Antarctic Environmental Protocol which contains explicit references to animal welfare (annex II, art. 3.6). Nevertheless, when it comes to addressing the conservation of biodiversity as a whole, animal welfare is clearly a secondary concern with regards to more holistic approaches.

${ }^{38}$ United Nations, General Assembly, Harmony with Nature, A/RES/72/223, 20 December 2017. This resolution is the latest in a series of resolutions with the same title. The first one was adopted in December 2009 and initiated a process of institutional work in order to promote 'the construction of a new, non-anthropocentric paradigm in which the fundamental basis for right and wrong action concerning the environment is grounded not solely in human concerns'. For more information, see www.harmonywithnatureun.org/. 
the ICJ in the Certain Activities carried out by Nicaragua in the Border Area case strengthens the legal paradigm of a holistic approach for the conservation of biodiversity. ${ }^{39}$ In this historic decision in which the ICJ granted compensation for environmental damage for the first time, ${ }^{40}$ the Court decided to evaluate the damage caused to the environment by considering the affected ecosystem in its entirety. ${ }^{41}$ When doing so it referred to several concepts: in particular, to the concept of ecosystem services. ${ }^{42}$ Ecosystem services refer to the direct and indirect contributions of ecosystems to human well-being. These contributions can be attributed a value in order to determine the economic importance of ecosystems. ${ }^{43}$ In this case, by referring to this concept, the ICJ stressed once more the anthropocentric and ecosystemic aspect of international biodiversity law. The recognition of this paradigm for the valuation of biodiversity by the judicial organ of the United Nations is telling of how little the question of animal welfare seems to bear on the evolution of this branch of international law.

However, if animal welfare is but a faint consideration in general international biodiversity law, the diagnosis is quite the opposite when examining agreements concerned with endangered species.

\section{Animal Welfare: A Condition for the Sustainable Use and Conservation of Endangered Species}

Historically, international environmental law has developed through the adoption of treaties dealing with the conservation and sustainable use of specific species. These treaties had different raisons d'être, from the preservation of purely commercial interests ${ }^{44}$ to the conservation of species that were deemed useful. ${ }^{45}$ As the decades passed, and with the development of scientific knowledge on the global state of the environment and the conservation status of species, several other specific treaties were adopted in order to prevent extinctions. The instruments adopted during the

\footnotetext{
${ }^{39}$ ICJ, Certain Activities carried out by Nicaragua in the Border Area (Costa Rica v. Nicaragua), Judgement of 2 February 2018, ICJ Reports 2018.

${ }^{40}$ Ibid., para. 41.

${ }^{41}$ Ibid., para. 78 .

${ }^{42}$ Ibid., para. 52.

${ }^{43}$ This concept is currently at the centre of several international initiatives. It is one of the core concepts of the general framework of the Intergovernmental Platform on Biodiversity and Ecosystem Services (IPBES) and is being promoted by the Economics of Ecosystems and Biodiversity Initiative (TEEB) so as to influence decision-making across the globe. See www.ipbes.net/ and www.teebweb.org/.

${ }^{44}$ Agreement on Measures for Regulating the Catch and Conserving Stocks of Seals in the NorthEastern Part of the Atlantic Ocean, 22 November 1957, 309 UNTS 269.

${ }^{45}$ For instance, the Convention Internationale du 19 mars 1902 pour les Oiseaux Utiles à l'Agriculture, available at: www.admin.ch/opc/fr/classified-compilation/19020002/index.html.
} 
second half of the twentieth century no longer only dealt with specific species but also with practices such as international trade or with broader categories, such as migratory species. Yet, with the exception of the well-known example of the CITES, ${ }^{46}$ these different instruments make no mention of the concept of welfare, be it directly or indirectly, in their provisions. For instance, the GORILLA Agreement, ${ }^{47}$ adopted within the context of the Convention on Migratory Species, calls for the maintenance of gorillas 'in a favourable conservation status'. ${ }^{48}$ The same goes for the Agreement on the Conservation of Polar Bears, ${ }^{49}$ which states that its parties 'shall manage the bear population in accordance with sound conservation practice'. ${ }^{50}$ Other treaties generally prohibit the killing of individual members of certain species $^{51}$ but do not provide any other indication on how to ensure that the same individuals are not subjected to unnecessary suffering due to restrictions to their animal freedoms by human activities.

At first glance, it appears that the welfare of individual members of those specific species concerned by these numerous instruments is not considered essential for their conservation. However, most international environmental treaties have an evolutive purpose by design ${ }^{52}$ and their main provisions are often followed by decisions and guidelines ${ }^{53}$ that allow for an updated implementation in order to achieve greater effectiveness. This process of legal densification ${ }^{54}$ of the primary obligations of states with regard to the conservation of certain species has paved the way for considerations of welfare. For instance, with regards to the conservation of cetaceans, the influence of welfare on the obligations of states is increasingly clear. This is most notable in the context of the International Whaling Commission, where its members have adopted several decisions aiming at ensuring the welfare of

\footnotetext{
${ }^{46}$ Convention of International Trade in Endangered Species of Wild Fauna and Flora (CITES), 1973 (n. 26). See, inter alia, art. III.2.c, 'An export permit shall only be granted when the following conditions have been met (...): a Management Authority of the State of export is satisfied that any living specimen will be so prepared and shipped as to minimize the risk of injury, damage to health or cruel treatment' (emphasis added).

${ }^{47}$ Agreement on the Conservation of Gorillas and their Habitats, 26 October 2007, 2545 UNTS 55. ${ }^{48}$ Art. II.

${ }^{49}$ Agreement on the Conservation of Polar Bears, 15 November 1973, 2898 UNTS I-50540.

${ }^{50}$ Art. II.

${ }^{51}$ Such as the agreements and memoranda of the 'CMS family', i.e. all the international agreements, formal or informal, adopted in order to implement the CMS with regards to specific migratory species. For an overview of the formal agreements, see www.cms.int/en/cms-instruments/ agreements.

${ }^{52}$ As underlined by the ICJ. ICJ, Case Concerning the Gabčikovo-Nagymaros Project (Hungary v. Slovakia), Judgement of 25 September 1997, ICJ Reports 1997, 7, para. 104.

${ }^{53}$ Mostly decisions by the meeting of the parties held on a regular basis (once every two to three years).

${ }^{54}$ On this topic, see Churchill/Ulfstein, 'Autonomous Institutional Arrangements' 2000; Brunnée, 'COPing with Consent' 2002; Wiersema, 'New International Law-Makers?' 2009.
} 
cetaceans falling under the scope of the commission. ${ }^{55}$ Moreover, several decisions taken in other international fora encourage states to take into consideration the cultures of whale populations in their conservation effort. ${ }^{56}$ Similar developments focusing on welfare can be seen in the context of other species-related treaties. The parties to the EUROBATS agreements ${ }^{57}$ have adopted decisions specifying how injured individual bats should be taken care of before being released into the wild. ${ }^{58}$ In the context of the Agreement on the Conservation of Albatrosses and Petrels (ACAP),${ }^{59}$ several technical guidelines, which can be used as interpretive tools for the general provisions of the agreement, ${ }^{60}$ were produced to ensure the welfare of individuals (e.g. the guidelines on translocation). ${ }^{61}$

Witnessing the evolution of international treaties dealing with the conservation and sustainable use of specific species, one gains the impression that the welfare of individuals is gradually becoming a prerequisite for the conservation of species as a whole. As the knowledge of species and the pressures they endure grows, it is apparent that ensuring their conservation cannot simply be confined to the strict application of the main provisions of international agreements. Not killing, or killing within commonly agreed limits (for instance, on the basis of quotas), is insufficient on its own to preserve the specie, and so is 'simply' preserving habitats. Active steps must be taken by the parties to these international instruments in order to guarantee collective welfare and thus effectively achieve conservation and sustainable use.

However, there are two limits to this diagnosis that seem to equate animal welfare and international biodiversity law. Firstly, the provisions concerning welfare are mostly contained in secondary rules or technical guidelines. As such, they are not binding. This leaves considerable leeway to the states in enforcing them. Secondlyand this is the greatest limitation-even though the influence of animal welfare in the evolution of these specific instruments is clear, they only concern a very small proportion of wildlife, namely species that have been recognised as endangered and that are the object of international rules. Solely based on these agreements, it would be a gross overstatement to claim that the welfare of wildlife is guaranteed by international biodiversity law.

\footnotetext{
${ }^{55}$ This aspect has been abundantly commented upon. See, for instance, Harrop, 'From Cartel to Conservation', 2003.

${ }^{56}$ CMS, Résolution 11.23 (2014), Conservation Implications of Cetacean Culture, para. 2. The consideration for the culture of Cetaceans has subsequently been added to decisions of other cetacean-related instruments, such as the ACCOBAMS in the Mediterranean region: ACCOBAMS, Resolution 6.14 (2016), Population Structure Studies (the resolution cites the CMS resolution in its opening considerations).

${ }^{57}$ Agreement on the Conservation of Bats in Europe (EUROBATS), 4 December 2012, 1863 UNTS 101.

${ }^{58}$ EUROBATS, Résolution 7.10 (2014), Bat Rescue and Rehabilitation.

${ }^{59}$ Agreement on the Conservation of Albatrosses and Petrels, 19 June 2001, 2258 UNTS 257.

${ }^{60}$ As provisioned by art. 32 (complementary means of interpretation) of the Vienna Convention on the Law of Treaties, 23 May 1969, 1155 UNTS 331.

${ }^{61}$ Jacobs/Deguchi/Perriman et al., Guidelines 2015, available at: https://www.acap.aq/en/resources/ acap-conservation-guidelines/2640-translocation-guidelines/file.
} 
Hence, it can be said that international biodiversity law, in its general and specific aspects, does not constitute an appropriate tool to ensure the welfare of wildlife in its entirety. International biodiversity law concerns itself with animal welfare only when it deals with the conservation and sustainable use of specific species or the regulation of certain practices, as welfare becomes a condition for the achievement of its purpose. ${ }^{62}$ Consequently, this welfare gap in international biodiversity law means that specific rules would have to be enacted in order for the welfare of wildlife to be protected at the international level. The following section will show that such rules, though they may have a purpose that is distinct from conservation or sustainable use, could complement international biodiversity law.

\section{The Relevance of Complementary International Rules to Ensure Both Wildlife Welfare and Conservation}

It is important to stress that while welfare and conservation do not have the same ethical basis (individualist versus collective) they might lead to similar practices and end results. ${ }^{63}$ This section will examine whether a specific set of rules concerning animal welfare at the global level could fill the gaps in international biodiversity law and complement its existing dispositions.

Several authors have called for the adoption of international instruments and/or rules specifically designed to ensure the protection of animals as individuals. ${ }^{64}$ In doing so, they argue that the lack of rules that could guarantee the welfare of wildlife is morally unsatisfactory with regard to the unnecessary suffering that human activities cause to individual animals, both captive and wild. ${ }^{65}$ For instance, in an article published in 2012, David Favre argued in favour of the adoption of a framework convention that would establish common principles regarding the welfare of animals at the international level. ${ }^{66}$ Such a convention would contain articles

\footnotetext{
${ }^{62}$ Stuart Harrop has suggested that as biodiversity declines, welfare considerations will become increasingly predominant in international environmental law. The rationale is that the few remaining wild animals will have to be preserved by fully taking into account all the elements necessary for their welfare: Harrop, 'Climate Change' 2011.

${ }^{63}$ For instance, the question of traps and their indiscriminate and cruel effect on wildlife is simultaneously a concern for conservationists and welfarists alike. On the interplay between welfare and conservation with regards to cetaceans, see Harrop, 'From Cartel to Conservation' 2003.

${ }^{64}$ For instance, Favre, 'An International Treaty' 2012; Brels, 'A Global Approach', 2017b.

${ }^{65}$ Adam/Schaffner, 'International Law and Wildlife Well-Being' 2017; Scholtz, 'Injecting Compassion’ 2017.

${ }^{66}$ Favre, 'An International Treaty' 2012.
} 
calling for a reduction of the killing and unnecessary suffering of wildlife, as well as the preservation of habitats.

In addition to the ethical arguments, it is also relevant to underline the fact that welfare considerations can be useful for the conservation of populations, thus setting the plea for the welfare of wildlife in the context of environmental ethics. ${ }^{67}$ For instance, several studies have demonstrated how high stress levels in individuals can affect the overall population. This factor can influence the success rates of species reintroduction practices ${ }^{68}$ or aggravate the spread of diseases within a population. ${ }^{69}$ At the international level, the ongoing effort to mitigate the adverse impact of anthropogenic noise on cetaceans is a clear illustration that welfare and conservation can be intertwined. ${ }^{70}$

This goes to show that enacting international rules for the welfare of animals, and ipso facto wildlife, could serve the double purpose of filling the ethical gap with regard to the impact of human activities on animals and strengthening existing conservation regimes. Rules concerned with animals as individuals can complement rules concerned with animals as species. ${ }^{71}$ The last question then is to determine what form such rules would take. ${ }^{72}$

As mentioned earlier, several authors have called for an international treaty that would exclusively deal with the question of welfare and animal rights. ${ }^{73}$ An alternative to a stand-alone treaty would be to insert elements of welfare into existing or future environmental agreements. For instance, the UNGA has recently adopted a resolution launching a process that could eventually lead to the adoption of a Global Environment Pact. ${ }^{74}$ Such a pact could possibly call for the due consideration of

\footnotetext{
${ }^{67}$ Paquet/Darimont, 'Wildlife conservation and animal welfare' 2007, 179: 'The integrity of habitats and the populations they contain are inextricably linked to the welfare of the individual animals that constitute this population and occupy those habitats'.

${ }^{68}$ Hing et al., 'Relationship between physiological stress and wildlife disease' 2016.

${ }^{69}$ Teixeira et al., 'Revisiting translocation' 2007.

${ }^{70}$ Anthropogenic noise and the stress it generates for individual cetaceans has been linked to higher mortality rates and stranding. See, inter alia, Thorne/Johnston, 'Response of Cetaceans' 2007. This topic raises complex legal question on how to reduce and mitigate their adverse effects. See Scott, 'International Regulation of Undersea Noise' 2004; Firestone/Jarvis, 'Response and Responsibility 2007.

${ }^{71}$ Though it must be stressed that it is not systematically the case. For instance, welfare rules could prohibit the use of traps or practices that are particularly cruel but do not have a significant impact on the conservation of the population as a whole.

${ }^{72}$ Discussing their exact content falls outside of the scope of this chapter. For references, see n. 64 above.

${ }^{73}$ See n. 64 above.

${ }^{74}$ United Nations, General Assembly, Towards a Global Pact for the Environment, A/72/L.51, 7 May 2018. A first draft of the pact has been elaborated by a French think tank ('le club des juristes') and is available at: http://pactenvironment.org/fr/.
} 
animal welfare in environmental conservation, especially considering the fact that a growing number of states have enacted laws with regard to the protection of animal wellbeing. ${ }^{75}$ For instance, an additional line calling for the prevention of unnecessary suffering could be added to the current art. 2 (duty to take care of the environment) which states that:

Every State or international institution, every person, natural or legal, public or private, has the duty to take care of the environment. To this end, everyone contributes at their own levels to the conservation, protection and restoration of the integrity of the Earth's ecosystem. ${ }^{76}$

Consideration for animal welfare could also be added to the normative corpus of existing regimes. For instance, the CBD's Aichi Targets will be renewed in $2020 .^{77}$ Putting consideration of animal welfare into the renewed targets could ensure that all biodiversity related conventions are implemented not only to ensure conservation but also welfare. Indeed, these Targets have been widely adopted by other multilateral environmental agreements and now constitute commonly shared goals. ${ }^{78}$ One can expect the next set of targets to also be included in the normative framework of other biodiversity-related regimes.

These are, of course, optimistic suggestions. Regrettably, international environmental law is largely ineffective, and adding considerations of animal welfare to it would not necessarily lead to an improvement. However, it would constitute a first step that could complement existing national and regional initiatives and encourage states to consider wildlife in their existing animal welfare laws. The most difficult questions lie in the necessary actions that need to be taken in order to move from ideas to concrete and effective realisations.

\section{References}

Adam, R., \& Schaffner, J. (2017). International law and wildlife well-being: Moving from theory to action. Journal of International Wildlife Law and Policy, 20, 1-17.

Bar-On, Y. M., Phillips, R., \& Milo, R. (2018, June 19). The biomass distribution on earth. Proceedings of the National Academy of Science, 115(25), 6506-6511.

Bowman, M., Davies, P., \& Redgwell, C. (2010). Lyster's international wildlife law (2nd ed.). Cambridge: CUP.

Brels, S. (2017a). A global approach to animal protection. Journal of International Wildlife Law and Policy, 20, 105-123.

\footnotetext{
${ }^{75}$ The ubiquity of animal welfare provisions in national legislations has led some authors to ponder whether or not animal welfare could be considered a principle of international law. See Sykes, 'Nations Like Unto Yourselves' 2011.

${ }^{76}$ See n. 74 above.

${ }^{77}$ In 2020, the current strategic plan of the CBD will be terminated and replaced with another that will take into consideration the successes and failures of its predecessor. The current plan was adopted using this process when it was recognised that the plan adopted in 2002 had not produced the expected results.

${ }^{78}$ Futhazar, 'The Diffusion of the Strategic Plan for Biodiversity' 2015.
} 
Brels, S. (2017b). Le Droit du Bien-Être Animal dans le Monde: Evolution et Universalisation. Paris: L'Harmattan.

Brunnée, J. (2002). Coping with consent: Law making under multilateral environmental agreements. Leiden Journal of International Law, 15, 1-52.

Churchill, R., \& Ulfstein, G. (2000). Autonomous institutional arrangements in multilateral environmental agreements: A little-noticed phenomenon in international law. American Journal of International Law, 94, 623-659.

Davison, N., \& Coates, D. (2011). The Ramsar Convention and synergies for operationalizing the convention on biological diversity's ecosystem approach for wetland conservation and wise use. Journal of International Wildlife Law and Policy, 14, 199-205.

De Lucia, V. (2015). Competing narratives and complex genealogies: The ecosystem approach in international environmental law. Journal of Environmental Law, 27, 91-117.

Favre, D. (2012). An international treaty for animal welfare. Animal Law, 18, 237-280.

Firestone, J., \& Jarvis, C. (2007). Response and responsibility: Regulating noise pollution in the marine environment. Journal of International Wildlife Law and Policy, 10, 109-152.

Futhazar, G. (2015). The diffusion of the strategic plan for biodiversity and its Aichi biodiversity targets within the biodiversity cluster: An illustration of current trends in the global governance of biodiversity and ecosystems. Yearbook of International Environmental Law, 25, 133-166.

Garric, A. (2016, March 29). L214, la méthode choc pour dénoncer les abattoirs. Le Monde.

Guichet, J.-L. (2013). La question animale dans l'éthique environnementaliste. Journal International de Bioéthique, 24, 29-38.

Harrop, S. (2003). From Cartel to Conservation and on to compassion: Animal welfare and the international whaling commission. Journal of International Wildlife Law and Policy, 6, 79-104.

Harrop, S. (2011). Climate change, conservation and the place for wild animal welfare in international law. Journal of Environmental Law, 23, 441-462.

Hing, S., Narayan, E. J., Thompson, R. C. A., et al. (2016). The relationship between physiological stress and wildlife disease: Consequences for health and conservation. Wildlife Research, 43, 51-60.

Jacobs, J., Deguchi, T., Perriman, L., Flint, E., Hummer, H., \& Uhart, M. (2015) Guidelines for translocations of albatrosses and petrels (ACAP Secretariat: Macquarie 2015), available at: https://www.acap.aq/en/resources/acap-conservation-guidelines/2640-translocation-guidelines/ file.

Kolbert, E. (2014). The sixth extinction: An unnatural history. London: Henry Holt and Co.

Morgera, E., \& Razzaque, J. (2017). Biodiversity and nature protection law. Cheltenham: Edward Elgar.

Nouët, J.-C. (2013). L'Animal Sauvage au regard du droit et de l'éthique en France. Journal International de Bioéthique, 24, 65-76.

Paquet, P. C., \& Darimont, C. T. (2010). Wildlife conservation and animal welfare: Two sides of the same coin. Animal Welfare, 19, 177-190.

Peters, A. (2016). Global animal law: What it is and why we need it. Transnational Environmental Law, 5, 9-23.

Sagoff, M. (1983). Animal Liberation and environmental ethics: Bad marriage, quick divorce. Osgoode Hall Law Journal, 22, 297-307.

Scholtz, W. (2017). Injecting compassion into international wildlife law: From conservation to protection? Transnational Environmental Law, 6, 463-483.

Scott, K. (2004). International regulation of Undersea noise. International and Comparative Law Quarterly, 24, 287-392.

Sykes, K. (2011). Nations like unto yourselves: An inquiry into the status of a general principle of international law on animal welfare. Canadian Yearbook of International Law, 49, 3-49.

Teixeira, C., Schetini de Azevedo, C., Mendl, M., Cpreste, C. F., et al. (2007). Revisiting translocation and reintroduction programmes: The importance of considering stress. Animal Behaviour, 73, 1-13. 
Thorne, L. H., \& Johnston, D. W. (2007). Response of cetaceans to anthropogenic noise. Mammal Review, 37, 81-115.

Weil, K. (2010). A report on the animal turn. Differences, 21, 1-23.

Wiersema, A. (2009). The new international law-makers? Conferences of the parties to multilateral environmental agreements. Michigan Journal of International Law, 31, 231-302.

Guillaume Futhazar is a senior research fellow at the Max Planck Institute for Comparative Public Law and International Law. He holds a Ph.D. in Public Law from Aix-Marseille University. His current research deals with, inter alia, international environmental law, the interrelations between law and science, and regime interactions.

Open Access This chapter is licensed under the terms of the Creative Commons Attribution 4.0 International License (http://creativecommons.org/licenses/by/4.0/), which permits use, sharing, adaptation, distribution and reproduction in any medium or format, as long as you give appropriate credit to the original author(s) and the source, provide a link to the Creative Commons licence and indicate if changes were made.

The images or other third party material in this chapter are included in the chapter's Creative Commons licence, unless indicated otherwise in a credit line to the material. If material is not included in the chapter's Creative Commons licence and your intended use is not permitted by statutory regulation or exceeds the permitted use, you will need to obtain permission directly from the copyright holder. 